\title{
Intestinal Perforation as a Complication of Induced Abortion - a Case Report and Review of Literature
}

\author{
IP Alam ${ }^{1}$, Z Pervin ${ }^{2}$, MA Haque ${ }^{3}$
}

\begin{abstract}
Intestinal perforation is a rare complication of induced abortion but it is not rare in our country. It is most commonly seen in countries in which abortions are performed by people without proper training and with sharp pointed instruments without knowledge of anatomy. Bowel perforation occurs when the posterior vaginal wall or uterus is violated, allowing the instrument to pierce underlying structures. The ileum and sigmoid colon are the most commonly injured portions of bowel due to their anatomic location. Here we discussed a woman who sustained a perforation at anterior rectal wall from abortion and was managed successfully.
\end{abstract}

Key words: Intestinal perforation, uterine perforation, induced abortion.

\section{Introduction :}

Unsafe abortion is defined as the terminating an unintended pregnancy either by individuals without the necessary skills or in an environment that does not conform to minimum medical standards, or both ${ }^{1}$. Every year around 580,000 women die due to the complications of pregnancy and delivery according to World Health Organization (WHO) statistics ${ }^{2}$. There is an annual rate of around 50 million abortions worldwide, one-third of which are 'unsafe'. Ninety five percent of all induced abortions occur in developing countries $^{3}$.

Being illegal/non-religious, in our country induced abortions are performed by untrained personnel usually lady health visitors, untrained birth attendants and nurses in dirty environment with subsequent high risk of haemorrhage, infection and injury to genital tract, or gastro intestinal tract. In Bangladesh, the most important causes of maternal deaths are eclampsia, septic abortion, postpartum sepsis, obstructed labour, antepartum and postpartum hemorrhage ${ }^{4}$. It is observed that prior to deaths, most of the pregnancies were

1. Dr. Irin Parveen Alam, FCPS, MS (Obst \& Gynae), Assistant Prof. Department of Obstetrics \& Gynae, FMC, Faridpur.

2. Dr. Zebunnessa Pervin, MCPS, DGO, FCPS (Obst \& Gynae), Assistant Prof. Department of Obstetrics \& Gynae, FMC, Faridpur.

3. Dr. Mohd. Azharul Haque, DTCD, FCPS (Medicine), Assistant Prof. Department of Medicine, SSMC \& Mitford Hospital, Dhaka.

Address of correspondence

Dr. Irin Parveen Alam, FCPS, MS (Obst \& Gynae), Assistant Prof. Department of Obstetrics \& Gynae, FMC, Faridpur. Mobile: 088-

0171-5348398,E-mail: dririn.alam@yahoo.com attended either by traditional practitioners or are not attended at all ${ }^{5}$.

Unsafe abortion is estimated to account for $13 \%$ of all maternal deaths worldwide. About half of all deaths from unsafe abortion are in Asia, and most of the remainder $(44 \%)$ is in Africa ${ }^{6}$. Morbidity is a much more common consequence of unsafe abortion than mortality. Complications include hemorrhage, sepsis, peritonitis, and trauma to the cervix, vagina, uterus and abdominal organs. Up to $50 \%$ of women who have unsafe abortions are hospitalized for complications ${ }^{7}$.

\section{Case :}

A 31-year-old multiparous (G4, P3) pregnant woman with pelvic pain and foul smelling pervaginal discharge was admitted to emergency department of Faridpur Medical College Hospital (FMCH). Her blood pressure was $90 / 60 \mathrm{mmHg}$; pulse- $120 / \mathrm{min}$; temperature $-102^{\circ} \mathrm{F}$. She had distended tender abdomen and foul smelling pervaginal discharge. Ultrasonographic examination revealed an irregular shadow in uterus with moderate collection in pouch of Douglas suggestive of incomplete abortion with moderate collection in peritoneal cavity. $\mathrm{X}$-ray abdomen in erect posture revealed gas shadow under the dome of diaphragm. Patient was asked about any history of induced abortion, but she at first refused and finally mentioned. It was her unplanned pregnancy and she went to a dai for termination. After that she felt severe pain in abdomen which was not subsided by any 
medicine and her condition gradually worsened. When she could not tolerate, she was transferred to hospital for further management. After admission patient was diagnosed as a case of perforation of uterus. She was resuscitated and underwent emergency laparotomy. On laparotomy, huge amount of foul smelling dark coloured peritoneal fluid came out. A rent was found in lower part of posterior surface of uterus. A macerated fetus with skull bone and limb bones found outside uterus, margin of uterus was lacerated, irregular and blackish in colour, so subtotal hysterectomy was done (Fig-1).

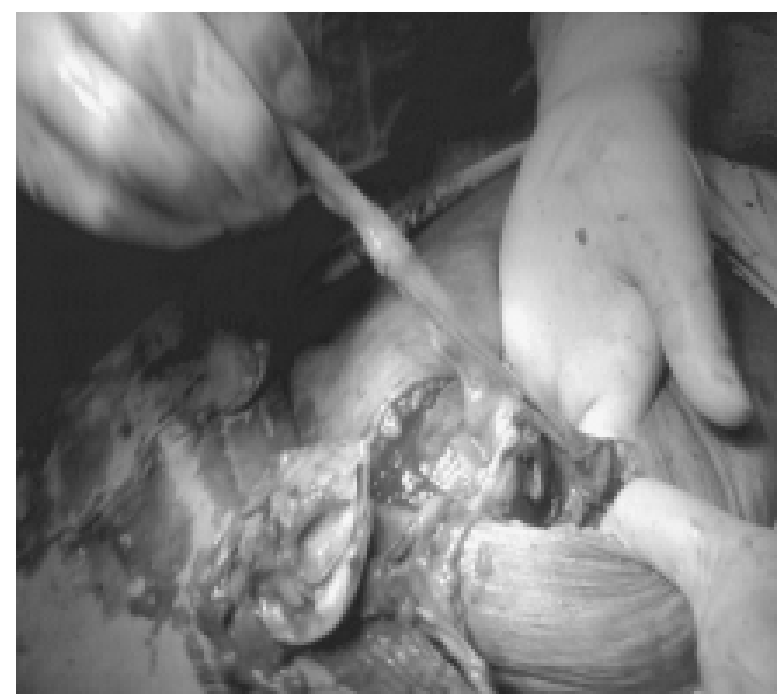

Fig-1: Showing fetal umbilical cord, detached fetal skull bone.

After toileting a large gap in anterior rectal wall was found, with the help of a surgeon colostomy was done (Fig-2). Post operatively patient was managed with antibiotic, fluid and blood. The patient was discharged after $10^{\text {th }}$ postoperative day with an advised to close colostomy after three months. Later after three months colostomy was closed.

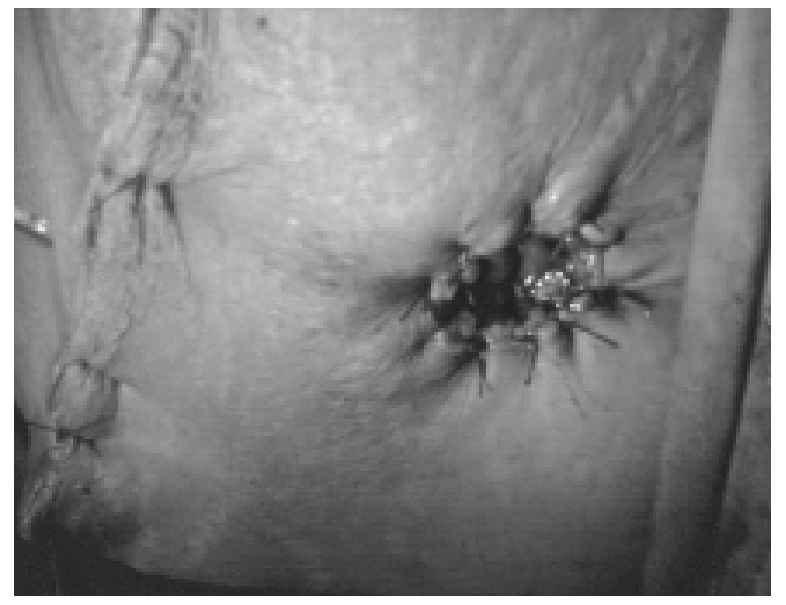

Fig 2: After operation wound and colostomy site.

\section{Discussion :}

Every year, 50 million abortions occurs worldwide ${ }^{1}$. About 19-20 million of them are unsafe abortions and an estimated 68000 women die as a result. A high proportion of maternal deaths caused by abortion are especially due to illegal unsafe abortion. In Bangladesh, approximately 1.2 million pregnancies (31\%) are unplanned each year despite the Bangladesh Family Planning Program's intense efforts during the past years to help couples to achieve their reproductive goals ${ }^{7}$. The official estimate indicates that about $120,000 \mathrm{MR} /$ abortions are performed every year, but unofficial estimates put it as high as $800,000{ }^{7,8}$. Many of these MR/abortions result in serious maternal morbidities and/or deaths. According to a study, approximately 8,000 women in Bangladesh die each year due to abortion-related complications ${ }^{8}$.

Nearly all unsafe abortions (97\%) are in developing countries ${ }^{9}$. Unsafe abortion is usually associated with complications such as, abnormal vaginal discharge, fever, septic shock which occur as a result of low resource setting such as lack of sterile equipment, use of sharp or inappropriate objects. It was found that infection is seen in up to $51 \%$ of illegal abortions. Invasive methods, such as insertion of tubes or liquids into the uterus, were more successful compared to other methods. However, these more invasive methods are associated with increased risks. Foreign bodies inserted into the uterus to disrupt the pregnancy can damage the uterus and internal organs, including bowel even urinary bladder. Knitting needles, A flexible rubber catheter, MR cannula, straight wooden stick or roots were common methods ${ }^{10}$.

It has been observed that people are concerned more about the side effects of different methods of contraception like insertion of intra uterine contraceptive device, using injections or pills but refuse to understand the hazards of unsafe abortions by unskilled persons ${ }^{11}$. World wide millions of women seek induced abortions which if successful and complete remain a secret and if complicated get highlighted due to their management at hospital level. The hospital data represents just tip of the ice berg. The problem at community level is much bigger and graver. It is a problem that puts an extra burden on already over worked staff and limited resources of government hospitals. Septic induced abortion is an important cause of maternal morbidity and mortality and is completely preventable ${ }^{12}$. 
Septic abortion is the one that gets complicated with infection and is associated with fever, endometritis and parametritis, peritonitis. Acute consequences of pelvic inflammatory disease can spread to the state of septicemia and Disseminated Intravascular Coagulation especially in the presence of low resistance of the patient and high virulence of organisms. In chronic phase, patient faces chronic pelvic inflammatory disease with consequent dyspareunia, dysmenorrhoea and infertility. All these consequences occur in the back ground of an unwanted pregnancy being terminated by an untrained lady health visitors or dai in a dirty environment with the promise of maintaining secrecy ${ }^{13}$.

The process of abortion in Bangladesh in considered sinful and law also prohibits it but despite this, large numbers of abortions are conducted in the country irrespective of fear of procedure, legal implications and religious beliefs. Many of such cases go un-noticed as patients conceal the history of handling and just present with incomplete miscarriage ${ }^{13}$.

A study reveals that among the unintended pregnancies that are due to contraceptive failure; $31 \%$ undergo menstrual regulation, $4.9 \%$ seek for induced abortion ${ }^{7}$. The incidence of abortions contributes to one quarter of all maternal deaths in Bangladesh $^{14}$.

The number of pregnancy termination performed in Bangladesh, either through legal or traditional means is unknown ${ }^{15}$. It is very difficult to identify and record abortion, including induced abortion. These patients come in a moribund stage and one has to give multiple antibiotic cover to treat the infection and then resort to surgery like evacuation of the uterus, colpotomy to drain a pelvic abscess, or laparotomy to deal with visceral injuries. To improve the outcome, surgery should be done early rather than late ${ }^{16}$.

In a study in India, they show that among all complications, bowel injury is the most dangerous and lead to significant number of death, which mostly occurred among women undergoing abortion where criminal methods were used and there was no proper medication and follow-up. It also showed that higher mortality was associated with injury of large gut, and sooner the reparative surgery, the better was the $\operatorname{prognosis}^{16}$.
In other study it showed that Seventy-three percent $(11 / 15)$ of the patients who underwent laparotomy had concomitant injury to the bowels, $16.4 \%$ of the patients with septic abortion had intestinal injuries; the survival of those patients with intestinal injuries was very much dependent on the operative procedures adopted. When a dysfunction colostomy was raised, the mortality was nil. In patients who had simple closure of the perforation and in those who had primary resection and anastomosis, mortality was $66.6 \%{ }^{17}$.

\section{Conclusion :}

In the countries where abortion is illegal, consequences of induced abortion become a major reproductive health problem. Some times abortion becomes threatening to a mother, especially when performed illegally. Though concept of emergency contraceptive are wide practiced in our country, knowledge of this is not shared by the whole community. Women empowerment regarding their decision making on reproductive issues should be increased. Husbands should be involved in family planning and reproductive health programmes. Unsafe abortion is an important social and public health problem that causes significant morbidity and mortality especially in developing world. Prompt diagnosis and appropriate intervention might provide better outcome. Therefore early referral and safe abortion services by skilled personnel in peripheral centers are necessary to limit mortality and morbidity of unsafe abortion.

\section{References :}

1. Mundigo AI, Indriso C. World Health Organization. Abortion in the developing world. 1999, London; New York: Zed Books.

2. Medical methods for termination of pregnancy. WHO Technical Report Series, 871. 1997, Geneva: World Health Organization (WHO).

3. David H. Methodologic realities in service oriented abortion research. In: Coeytaux F, Leonard A, Royston E, editors. Methodological issues in abortion. New York: The population council;1989.p.39-52.

4. Goodburn EA, Gazi R, Chowdhury M. Beliefs and practices regarding delivery and postpartum maternal morbidity in Rural Bangladesh. Studies in family Planning 1995;26:22-32.

5. Fauveau V, Wojtyniak B, Koenig MA, Chakraborty J, Chowdhury AI. Epidemiology and Cause of Deaths among Women in Rural Bangladesh. International Journal of Epidemiology, 1989;18(1):138-9. 
6. Unsafe abortion: global and regional estimates of the incidence of unsafe abortion and associated mortality in 2003. 5th ed. 2007, Geneva: World Health Organization.

7. Akhter H. Medical Practice after Legalization of Abortion: Bangladesh. Prevention and Treatment of Contraceptive Failure. Landy U, Ratnam SS (eds.). NewYork: Plenum Press.

8. Rochat RW, Jabeen S, Rosenberg MJ, Khan AR, Obaidullah M, Gould P. Maternal and Abortion Related Deaths in Bangladesh 1978-79. International Journal of Gynaecology and Obstetrics 1981;19:155-64.

9. Maternal Health and Safe Motherhood Programme. The prevention and management of unsafe abortion: report of a technical working group, Geneva. 2006, Geneva, Switzerland, WHO, Division of Family Health.

10. Maternal Health and Safe Motherhood Programme. The prevention and management of unsafe abortion: report of a technical working group, Geneva. 2006, Geneva, Switzerland, WHO, Division of Family Health.

11. Fischer M, Bhatnagar J, Guarner J, Reagan S. Fatal Toxic shock syndrome associated with Clostridium Sordellii after medical abortion. N Engl J Med. 2005;353:2352-60.

12.Phillip G, Grimes DA. Septic abortion. N Eng J Med.1994;331: $310-14$.

13. Anisa F, Humaira N, Khalid K, Aziz-UN. Septic Induced Abortions. J Ayub Med Coll Abbottabad. 2008;20(4);145-8.

14. Bankole A, Singh S, Taylor H. Characteristics of women who obtain induced abortion: A world wide review. Int Fam Plann Persp.1999;25:68-77.

15. Pelon PNJ. Menstrual Regulation Impact on Reproductive Health in Bangladesh: A literature Review. Regional Workshop Papers. Population Council, Bangladesh.1998;14.

16. Gupta SK, Banerjee K, Dogra TD. Maternal Death and Induced Abortion- A critical analysis. A Journal of Family Welfare. 2000;46(1):56-60.

17. Megafu U. Bowel injury in septic abortion: the need for more aggressive management. Int J Gynaecol obstet. 1980;17(5): 450-3. 